\title{
An EIGENVALUE SOLUTION OF FUNCTIONALLY GRADED NANOBEAM with an ATTACHED SPRING MASS SYSTEM
}

\author{
Togay KÜPELI * \\ Yakup Harun ÇAVUŞ * \\ Büşra UZUN \\ Mustafa Özgür YAYLI
}

Received: 07.08.2021; revised: 10.09.2021; accepted: 08.10.2021

\begin{abstract}
Nanobeams are now widely used in numerous vibration frequency research. In this study, an eigenvalue problem has used to determine the vibration frequency analysis of the buckyball and spring attached to the end of the nanobeam. The vibration frequencies of the system may be discovered using a single $(2 \times 2)$ matrix in this eigenvalue problem. A mathematical method for analyzing sensors has attached to nanobeams is presented in this paper. The results, which is obtained in this study, has showed a result that has compatible with the flicker frequency studies conducted in the literature, and the results have presented in tables and graphics.
\end{abstract}

Keywords: Frequency, Carbon Nanotube, Buckyball, Eigenvalue Problem.

Yay Kütle Sistemi İle Birleştirilmiş Fonksiyonel Olarak Derecelendirilmiş Nanokirişin Özdeğer Problemi İle Çözümü

Öz: Nanokirişler günümüzde çok sayıda titreşim frekansı araştırmasında yaygın olarak kullanılmaktadır. $\mathrm{Bu}$ çalışmada, nanokirişin ucuna takılı halde bulunan buckyball ve yayın titreşim frekans analizini yapabilmek için bir özdeğer problemi kullanılmıştır. Bu özdeğer probleminde sistemin titreşim frekansları tek bir (2x2) matris kullanılarak hesaplanabilir. Bu çalışmada, nanokirişlere bağlı sensörleri analiz etmek için matematiksel bir yöntem sunulmaktadır. Bu makalede elde edilen sonuçlar literatürde yapılan titreşim frekansı çalışmaları ile uyumlu bir sonuç göstermiştir ve sonuçlar tablo ve grafiklerle sunulmuştur.

Anahtar Kelimeler: Frekans, Karbon Nanotüp, Buckyball, Özdeğer Problemi.

\footnotetext{
* Bursa Uludağ Üniversitesi, Mühendislik Fakültesi, İnşaat Mühendisliği Bölümü, 16059, Nilüfer/Bursa.

İletişim Yazarı: Togay KÜPELİ (togay-kupeli@hotmail.com)
} 


\section{INTRODUCTION}

Today, numerous studies and papers on nanostructured materials are being published with great anticipation. In most of them, vibration frequency analyzers are commonly available. We should clearly say that non-local elasticity theory is incorporated in these research most of the time. The definition of adequate mathematical models for nanostructures is a significant topic affecting the theoretical framework of nanostructures because controlled experiments containing nanoscale effects are both expensive and challenging. This work presents a new subject to compare the vibration frequency that will occur in the system by using the buckyball and nanobeam at the same time. With the data to be revealed as a result of this study, it aims to be a reference for those who will work in this direction and the topic in the literature.

The fact that non-local elasticity theory is so widely utilized has been the subject of numerous papers, and it gives a far more comfortable framework for studying nano elements at scale than classical elasticity theory. Classical elasticity theory is a scale-free theory that outstanding debts for small-scale effects result in small size. To circumvent the drawbacks of classical continuum models, Eringen (1972) has proposed the nonlocal elasticity theory. Pradhan and Phadikar (2009) have investigated nonlocal elasticity theory for vibration of nanoplates. Reddy (2007) has used nonlocal theory for bending, buckling and vibration of beams. Liu et al. (2008) have conducted delaminating buckling model based on nonlocal Timoshenko beam theory for microwedge indentation of a film/substrate system. Another study using Timoshenko beam theory have conducted by (Wang et al., 2008). Murmu and Pradhan's (2009) small-scale effect on the vibration of nonuniform nanocantilever based on nonlocal elasticity theory work, as noted in the previous paragraph, is an example of several studies on non-local elasticity. Lu et al. (2006) has published the work about dynamic properties of flexural beams using a nonlocal elasticity model. Aydogdu (2009), Civalek and Demir (2011) have used nonlocal beam theory in their studies.

FG nanobeams have also been the subject of numerous studies. As an example, we can use Rahmani and Pedram (2014), Eltaher et al. (2013), Yayli and Uzun (2020) and Yayli (2018). Setoodeh et al. (2011), Thai (2012), Yayli, Yanik and Kandemir (2015), Yayli, Kandemir (2017), Yayli (2015) buckling analyses of carbon nanotubes can be seen in these papers. Civalek et al. (2020) and Uzun et al. (2020) have conducted vibration and stability analysis of nanobeams in their studies. There are some recently published studies in the literature that are similar to our study in terms of content and scope. As an example, Akbaş (2019), Alimoradzadeh and Akbaş (2021), Arda and Aydogdu (2020), (Akbaş, 2019).

There are papers in the literature about carbon nanotubes and buckyballs, which will be included in this study. An example of these studies is torsional vibration of carbon nanotubebuckyball systems based on nonlocal elasticity theory have published by (Murmu et al., 2011). Dravid et al. (1993) has conducted buckytubes and derivatives: their growth and implications for buckyball formation. Murmu and Adhikari (2010) has studied on nonlocal vibration of carbon nanotubes with attached buckyballs at tip.

In this study, an eigenvalue problem has established for the vibration analysis of the buckyball and spring system attached to the nanobeam. In this eigenvalue problem, the vibration frequencies of the system can be found by using a single $(2 \times 2)$ matrix. This work presents a mathematical method for the analysis of sensors attached to nanobeam. Obtained data are presented in the form of tables and graphs. Figure 2, represents a functionally graded nanobeam with an attached spring mass system and the buckyball system used in the study.

\section{DEFINITION OF PROBLEM}

According to Eringen (1983), the stress field at a point $\mathrm{x}$ in an elastic continuum is reliant not only on the strain field at the point, but also on strains at all other points of the body. In Eq. 
(1), which has been created based on Eringen's definitions, the nonlocal stress tensor $\sigma$ at point $\mathrm{x}$ is expressed as

$$
\sigma=\int_{V} K\left(\left|x^{\prime}-x\right|, \tau\right) \mathrm{t}\left(x^{\prime}\right) \mathrm{dx}
$$

where $\mathrm{t}(x)$ is the classical, macroscopic stress tensor at point $\mathrm{x}$ and the kernel function $K\left(\left|x^{\prime}-x\right|, \tau\right)$ is the nonlocal modulus, $\left|x^{\prime}-x\right|$ being the distance and $\tau$ is a material constant that depends on internal and external characteristic.

It is possible Eringen (1983) to represent the integral constitutive relations in an equivalent differential form as

$$
\sigma-\left(e_{0} a\right)^{2} \nabla^{2} \sigma=C: \varepsilon
$$

in which $\varepsilon$ and $\mathrm{C}$ are the strain and elasticity tensors, respectively. $e_{0} a$ represents the nonlocal parameter. In all theories, the axial force-strain relation is the same and it is given by (Eringen, 1983)

$$
N-\left(e_{0} a\right)^{2} \frac{\partial^{2} N}{\partial x^{2}}=E A\left(\varepsilon_{\mathrm{xx}}^{0}\right)
$$

where the relations have been utilized.

$$
A=\int_{A} d A, \int_{A} z \mathrm{dA}=0
$$

As a result, the $\mathrm{x}$-axis follows the geometric centroid of the beam (Euler-Bernoulli Beam Theory). We only have $N$ and $M$ in this theory. The constitutive relations are defined as follows (Eringen, 1983):

$$
M-\left(e_{0} a\right)^{2} \frac{\partial^{2} M}{\partial x^{2}}=\text { EI }
$$

wherein $M$ represents moment, $\kappa$ is the curvature. The fourth-order partial differential equation of the nanobeam is given by Reddy (2007) according to nonlocal elasticity theory.

$$
E(r) I \frac{\partial^{4} w(x, t)}{\partial x^{4}}+\left[1-\left(e_{0} a\right)^{2} \frac{\partial^{2}}{\partial x^{2}}\right] \rho(r) A \frac{\partial^{2} w(x, t)}{\partial t^{2}}=0
$$

where $E(r)$ is the modulus elasticity of the functionally graded material, $\rho(r)$ is the density of the functionally graded material. $I$ is the moment of inertia of the cross-sectional area $A, a$ is the internal characteristic length, and $e_{0}$ is a material constant. The material variation is taken as follows:

$$
\begin{aligned}
& E(r)=\left(\left(E_{o}(r)-E_{i}(r)\right)\left(\frac{r}{R}\right)^{\beta}+E_{i}(r)\right) \\
& \rho(r)=\left(\left(\rho_{o}(r)-\rho_{i}(r)\right)\left(\frac{r}{R}\right)^{\beta}+\rho_{i}(r)\right)
\end{aligned}
$$


where $\rho_{i}(r)$ mass density of inner material, $\rho_{o}(r)$ mass density of outer material, $E_{i}(r)$ modulus of elasticity of inner material, $\beta$ represents FG index, $E_{o}(r)$ modulus of elasticity of outer material.

The lateral displacement $w(x, t)$ is used to examine the lateral vibration of the nanobeam.

$$
w(x, t)=\Psi(x) \cos (\omega \mathrm{t})
$$

$\omega$ where is the natural frequency and $\Psi(x)$ is the modal displacement function. On the basis of the identification of relationships between boundary points, the modal displacement function is defined as follows:

$$
w(x)=\left[\begin{array}{cc}
\Psi_{0} & x=0 \\
\Psi_{L} & x=L \\
\sum_{j=1}^{\infty} D_{j} \sin \left(\alpha_{j} x\right) & 0<x<L
\end{array}\right]
$$

in which $\Psi_{0}$ and $\Psi_{L}$ are the deflections at the boundary points, wherein

$$
\alpha_{j}=\frac{\mathrm{j} \Pi}{L}
$$

where $L$ is the nanobeam's length. In Eq. (10), the Fourier coefficient $\left(D_{j}\right)$ can be expressed as follows:

$$
D_{j}=\frac{2}{L} \int_{0}^{L} w(x) \sin \left(\alpha_{j} x\right) d x
$$

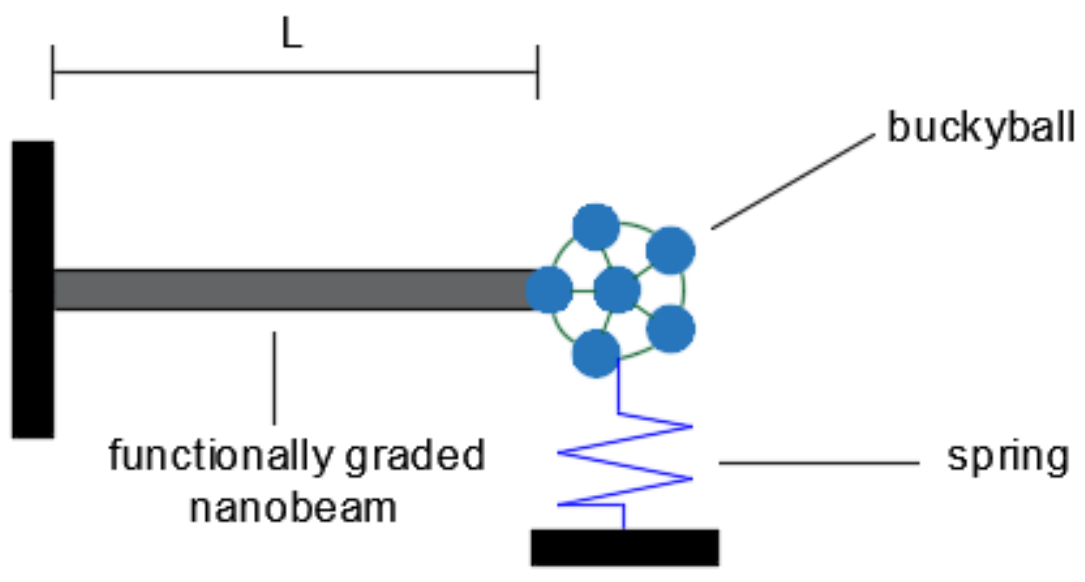

Figure 1:

Functionally graded nanobeam with an attached spring mass system with buckyball 
Eq. (10) is termwise differentiated to provide:

$$
w^{\prime}(x)=\sum_{k=1}^{\infty} \alpha_{j} D_{j} \cos \left(\alpha_{j} x\right)
$$

A Fourier cosine series can be used to express Eq. (13):

$$
w^{\prime}(x)=\frac{r_{0}}{L} \sum_{j=1}^{\infty} r_{j} \cos \left(\alpha_{j} x\right)
$$

In Eq. (14), the Fourier coefficients are given by

$$
\begin{aligned}
& r_{0}=\frac{2}{L} \int_{0}^{L} w^{\prime}(x) \partial x=\frac{2}{L}[w(L)-w(0)] \\
& r_{j=} \frac{2}{L} \int_{0}^{L} w^{\prime}(x) \cos \left(\alpha_{j} x\right) \partial x \quad(j=1,2 \ldots)
\end{aligned}
$$

We obtain the following results when we apply integration by parts:

$$
\begin{gathered}
r_{j=} \frac{2}{L}\left[w(x) \cos \left(\alpha_{j} x\right)\right]+\frac{2}{L}\left[\alpha_{j} \int_{0}^{L} w(x) \sin \left(\alpha_{j} x\right) \partial x\right. \\
r_{j=} \frac{2}{L}\left[(-1)^{j} w(L)-w(0)\right]+\alpha_{j} D_{j}
\end{gathered}
$$

The function's first derivative is then calculated as follows:

$$
\frac{\partial w(x)}{\partial x}=\frac{\psi_{L}-\psi_{0}}{L}+\sum_{j=1}^{\infty} \cos \left(\alpha_{j} x\right)\left(\frac{2\left((-1)^{j} \psi_{L}-\psi_{0}\right)}{L}+\alpha_{j} D_{j}\right)
$$

Stokes' transformation is the technique outlined above. By using Stokes' transformation as follows Eq. (20), the higher order derivatives of $w(x)$ can be obtained individually.

$$
\frac{\partial^{2} w(x)}{\partial x^{2}}=-\sum_{j=1}^{\infty} \alpha_{j} \sin \left(\alpha_{j} x\right)\left(\frac{2\left((-1)^{j} \psi_{L}-\psi_{0}\right)}{L}+\alpha_{j} D_{j}\right)
$$

$$
\begin{aligned}
& \frac{\partial^{3} w(x)}{\partial x^{3}}=\frac{\psi_{L} "}{L}-\psi_{0}{ }^{\prime \prime} \\
& \quad+\sum_{j=1}^{\infty} \cos \left(\alpha_{j} x\right)\left(\frac{2\left((-1)^{j} \psi_{L}{ }^{\prime \prime}-\psi_{0}{ }^{\prime \prime}\right)}{L}-\alpha^{2}{ }_{j} \frac{2\left((-1)^{j} \psi_{L}-\psi_{0}\right)}{L}+\alpha_{j} D_{j}\right)
\end{aligned}
$$


Küpeli T. et al: Eigenvalue Solution of Functionally Graded Nanobeam with an Spring System

$$
\frac{\partial^{4} w(x)}{\partial x^{4}}=-\sum_{j=1}^{\infty} \alpha_{j} \sin \left(\alpha_{j} x\right)\left(\frac{2\left((-1)^{j} \psi_{L}{ }^{\prime \prime}-\psi_{0}{ }^{\prime \prime}\right)}{L}-\alpha^{2}{ }_{j} \frac{2\left((-1)^{j} \psi_{L}-\psi_{0}\right)}{L}+\alpha_{j} D_{j}\right)
$$

Equations (20) and (22) are replaced into Eq. (6) to provide:

$$
\begin{aligned}
\sum_{j=1}^{\infty}\left(\frac { 2 } { L } \operatorname { c o s } ( \omega \mathrm { t } ) \operatorname { s i n } ( \alpha _ { j } x ) \left(-\mathrm{LD}_{j}\left(A\left(e_{0} a\right)^{2} \rho(r) \omega^{2} \alpha^{2}{ }_{j}+\rho(r) \mathrm{A} \omega^{2}-\mathrm{E}(r) \mathrm{I} \alpha^{4}{ }_{j}\right)\right.\right. \\
-2 \alpha_{j}\left((-1)^{j}\left(\psi_{L}\left(A\left(e_{0} a\right)^{2} \rho(r) \omega^{2}-\mathrm{E}(r) \mathrm{I} \alpha^{2}{ }_{j}\right)+\mathrm{E}(r) \mathrm{I} \psi_{L}{ }^{\prime \prime}\right)+\psi_{0}\left(\mathrm{E}(r) \mathrm{I} \alpha^{2}{ }_{j}\right.\right. \\
\left.\left.\left.-A\left(e_{0} a\right)^{2} \rho(r) \omega^{2}\right)+\mathrm{E}(r) \mathrm{I} \psi_{L}{ }^{"}\right)\right)=0
\end{aligned}
$$

In Eq (23), the Fourier coefficient can be written as follows in terms of $\psi_{0}, \psi_{L}, \psi_{0}{ }^{\prime \prime}$, and $\psi_{L}{ }^{\prime \prime}$ :

$$
\begin{gathered}
D_{j}=\frac{2\left(\omega^{2}\right)_{j}}{\alpha^{3}{ }_{j} L\left(e_{0} a\right)^{2} \alpha^{2}{ }_{j} \omega^{2}-\left(\omega^{2}\right)_{j}+\omega^{2}}\left(\left(\psi_{0}{ }^{\prime \prime}-(-1)^{j} \psi_{L}{ }^{\prime \prime}\right)-\alpha^{2}{ }_{j}\left(\psi_{0}-(-1)^{j} \psi_{L}\right)\right. \\
\left.+\frac{\omega^{2}}{\omega^{2}{ }_{j}} \alpha^{4}{ }_{j}\left(e_{0} a\right)^{2}\left(\psi_{0}-(-1)^{j} \psi_{L}\right)\right)
\end{gathered}
$$

The free vibration of a nanobeam with free boundaries at both ends is represented by the function $w(x, t)$.

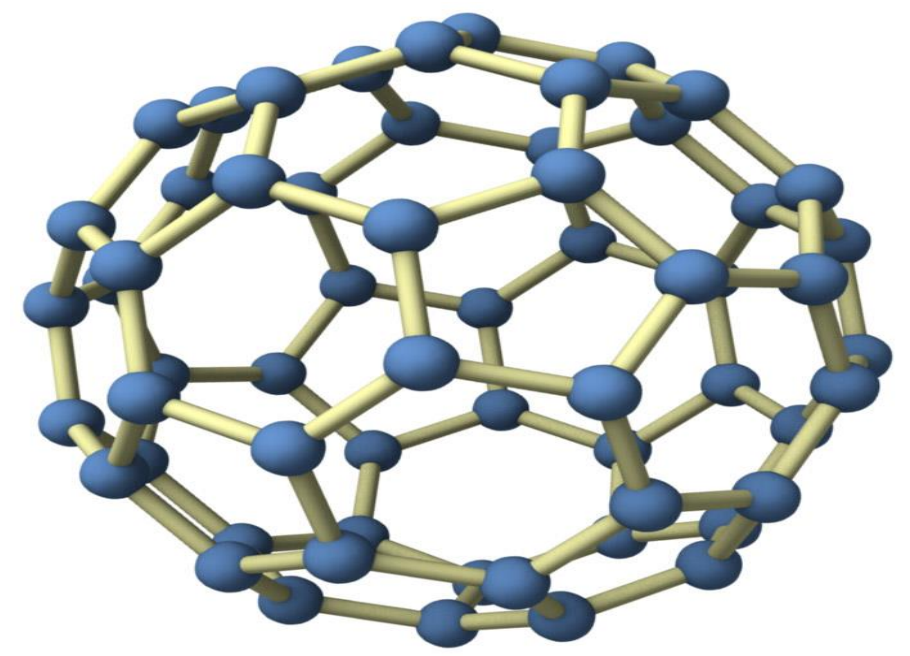

Figure 2:

Simplified version of buckyball

$$
\begin{aligned}
w(x, t)= & \sum_{j=1}^{\infty} \frac{2\left(\omega^{2}\right)_{j}}{\alpha^{3}{ }_{j} L\left(e_{0} a\right)^{2} \alpha^{2}{ }_{j} \omega^{2}-\left(\omega^{2}\right)_{j}+\omega^{2}}\left(\left(\psi_{0}{ }^{\prime \prime}-(-1)^{j} \psi_{L}{ }^{\prime \prime}\right)-\alpha^{2}{ }_{j}\left(\psi_{0}-(-1)^{j} \psi_{L}\right)\right. \\
& \left.+\frac{\omega^{2}}{\omega^{2}{ }_{j}} \alpha^{4}{ }_{j}\left(e_{0} a\right)^{2}\left(\psi_{0}-(-1)^{j} \psi_{L}\right)\right) \cos (\omega \mathrm{t}) \sin \left(\alpha_{j} x\right)
\end{aligned}
$$


This equation can be applied with any deformable boundary condition and is a more general version of the current technique.

\section{DEFINED BOUNDARIES}

Consider a cantilever nanobeam with a point mass at the free end and translational constraint at the other end (see Fig. 2). In mathematics, the boundary conditions are expressed as,

$$
\begin{gathered}
\psi_{0}=0, \frac{\partial \mathrm{w}(x, t)}{\partial x}=0, \quad x=0 \\
\psi_{L}{ }^{\prime \prime}=0, \mathrm{k} \psi_{L}-m \frac{\partial^{2} w(x, t)}{\partial t^{2}}=E I \frac{\partial^{3} \mathrm{w}(x, t)}{\partial x^{3}}, \quad x=L
\end{gathered}
$$

Substituting equations (19) and (21) into equations (26)-(27) yields two simultaneous homogeneous equations.

$$
\begin{gathered}
\left(1+\sum_{j=1}^{\infty} \frac{2 \lambda^{4}(-1)^{j}\left(\pi^{2} \Delta^{2} j^{2}+1\right)}{\lambda^{4}\left(\pi^{2} \Delta^{2} j^{2}+1\right)-j^{4}}\right) \psi_{L}+\left(K-m \pi^{2} \lambda^{4}+\sum_{j=1}^{\infty} \frac{2 \lambda^{4} \pi^{2} j^{2}}{\lambda^{4}\left(\pi^{2} \Delta^{2} j^{2}+1\right)-j^{4}}\right) \psi_{0}{ }^{\prime \prime} \\
=0 \\
\left(\sum_{j=1}^{\infty} \frac{2 j^{2}}{\pi^{2}\left(\lambda^{4}\left(\pi^{2} \Delta^{2} j^{2}+1\right)-j^{4}\right.}\right) \psi_{L}+\left(1+\sum_{j=1}^{\infty} \frac{2 \lambda^{4}(-1)^{j}}{\lambda^{4}\left(\pi^{2} \Delta^{2} j^{2}+1\right)-j^{4}}\right) \psi_{0}^{\prime \prime} \\
=0
\end{gathered}
$$

wherein

$$
\begin{gathered}
\lambda^{4}=\frac{\rho(r) \mathrm{AL}^{4} \omega^{2}}{\pi^{4} E(r) I} \\
K=\frac{\mathrm{kL}^{3}}{E(r) I} \\
\Delta=\frac{e_{0} a}{L}
\end{gathered}
$$

Equations (28) and (29) can be expressed as a matrix

$$
\left[\begin{array}{ll}
\Phi_{11} & \Phi_{12} \\
\Phi_{21} & \Phi_{22}
\end{array}\right]\left[\begin{array}{c}
\psi_{L} \\
\psi_{0}
\end{array}\right]=0
$$

where

$$
\Phi_{11}=1+\sum_{j=1}^{\infty} \frac{2 \lambda^{4}(-1)^{j}\left(\pi^{2} \Delta^{2} j^{2}+1\right)}{\lambda^{4}\left(\pi^{2} \Delta^{2} j^{2}+1\right)-j^{4}}
$$




$$
\begin{gathered}
\Phi_{12}=K-m \pi^{4} \lambda^{4}+\sum_{j=1}^{\infty} \frac{2 \lambda^{4} \pi^{2} j^{2}}{\lambda^{4}\left(\pi^{2} \Delta^{2} j^{2}+1\right)-j^{4}} \\
\Phi_{21}=\sum_{j=1}^{\infty} \frac{2 j^{2}}{\pi^{2}\left(\lambda^{4}\left(\pi^{2} \Delta^{2} j^{2}+1\right)-j^{4}\right.} \\
\Phi_{22}=1+\sum_{j=1}^{\infty} \frac{2 \lambda^{4}(-1)^{j}}{\lambda^{4}\left(\pi^{2} \Delta^{2} j^{2}+1\right)-j^{4}}
\end{gathered}
$$

An eigenvalue problem is defined in the equation given in (33). Eigenvalues can easily be found if the equation is set to " 0 " by adjusting the determinant of the coefficient matrix in Eq. (33).

$$
\left[\begin{array}{ll}
\Phi_{11} & \Phi_{12} \\
\Phi_{21} & \Phi_{22}
\end{array}\right]=0
$$

By providing the different characteristics of $(K)$ and $(m)$ according to the boundary condition, the characteristic equation of the aforementioned determinant may be determined.

\section{RESULTS AND DISCUSSION}

The vibration frequency analysis of the buckyball and spring attached to the end of the nanobeam was determined using an eigenvalue problem in this work. In this eigenvalue problem, a single (2x2) matrix can be used to find the system's vibration frequencies. The mechanical characteristics that were used in the study to determine vibration frequency values, $\rho_{i}(r)$ (mass density of inner material $)=4429 \mathrm{~kg} / \mathrm{m}^{3}, \rho_{o}(r)($ mass density of outer material $)=3000 \mathrm{~kg} / \mathrm{m}^{3}$, $E_{i}(r)$ (Modulus of Elasticity of inner material)=105.7 GPa, $E_{o}(r)$ (Modulus of Elasticity of outer material) $=151 \mathrm{GPa}$ and the $L$ parameter value specified as $100 \mathrm{~nm}$ and $200 \mathrm{~nm}, m$ (mass of buckyball) $=4, \mathrm{k}$ ( spring coefficient $)=5$. The unitless $\mathrm{m}$ and $\mathrm{k}$ values have been created to using in analysis for this study.

The vibration frequency values of the system which has shown in Figure 2 are given below in table and graph. Variable $\beta$ (FG index) values has used while calculating frequency parameters. 
Table 1. The frequencies $\left(10^{10} \mathrm{rad} / \mathrm{s}\right)$ of nanobeam with an attached spring mass system for diversified $\beta$ parameter $(\Delta=0.04$ and $L \rightarrow 100 \mathrm{~nm}$ )

\begin{tabular}{|lllllll|}
\hline & $\beta=0$ & $\beta=1$ & $\beta=2$ & $\beta=3$ & $\beta=4$ & $\beta=5$ \\
\hline Mode 1 & 0.4653 & 0.4268 & 0.4093 & 0.3991 & 0.3924 & 0.3876 \\
Mode 2 & 3.4737 & 3.1286 & 2.9616 & 2.8597 & 2.7901 & 2.7391 \\
Mode 3 & 5.5748 & 5.0210 & 4.7529 & 4.5895 & 4.4777 & 4.3959 \\
Mode 4 & 13.5818 & 12.2327 & 11.5795 & 11.1811 & 10.9089 & 10.7097 \\
Mode 5 & 17.4637 & 15.7289 & 14.8891 & 14.3769 & 14.0269 & 13.7706 \\
Mode 6 & 29.4838 & 26.5551 & 25.1371 & 24.2724 & 23.6815 & 23.2489 \\
\hline
\end{tabular}

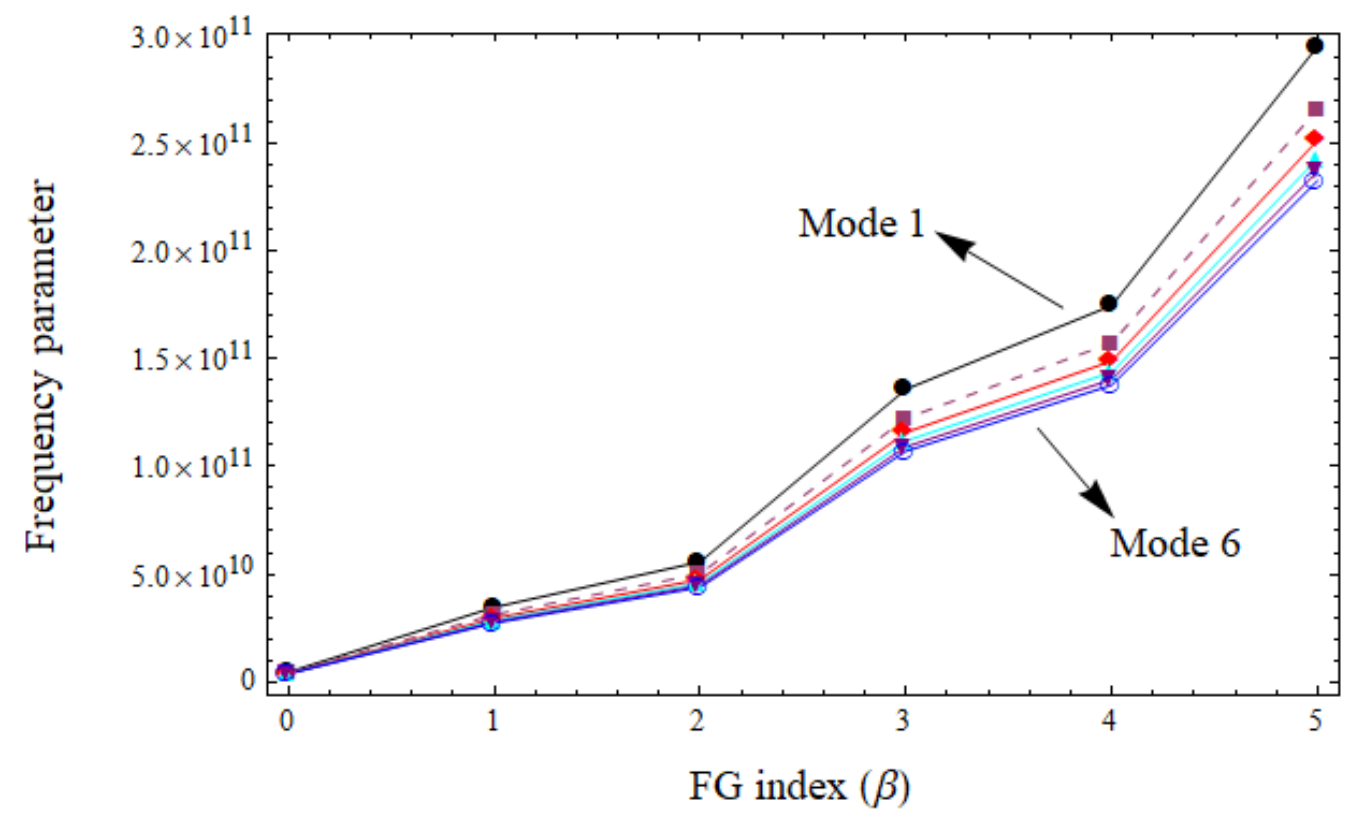

Figure 3:

Frequency parameter for diversified $\beta$ parameter

As can be easily observed in the table and graph given above, as parameter $\beta$ increases, natural frequency values are observed at the highest value for the mode 6 . While the lowest frequency value is seen in the first mode, a partial increase is observed in the progressive mode values. It has been observed that increasing the parameter value $\beta$ reduces the frequency of vibration. 
Küpeli T. et al: Eigenvalue Solution of Functionally Graded Nanobeam with an Spring System

Table 2. The natural frequencies $\left(10^{10} \mathrm{rad} / \mathrm{s}\right)$ of nanobeam with an attached spring mass system for various $\Delta$ parameter $(L \rightarrow 200 \mathrm{~nm}$ and $\beta=3)$

\begin{tabular}{|lcccc|}
\hline & $\Delta=0.00$ & $\Delta=0.025$ & $\Delta=0.04$ & $\Delta=0.1$ \\
\hline Mode 1 & 0.229 & 0.229 & 0.229 & 0.229 \\
Mode 2 & 1.158 & 1.154 & 1.147 & 1.096 \\
Mode 3 & 3.717 & 3.667 & 3.594 & 3.102 \\
Mode 4 & 7.738 & 7.517 & 7.207 & 7.178 \\
Mode 5 & 13.224 & 12.582 & 11.743 & 10.650 \\
\hline
\end{tabular}

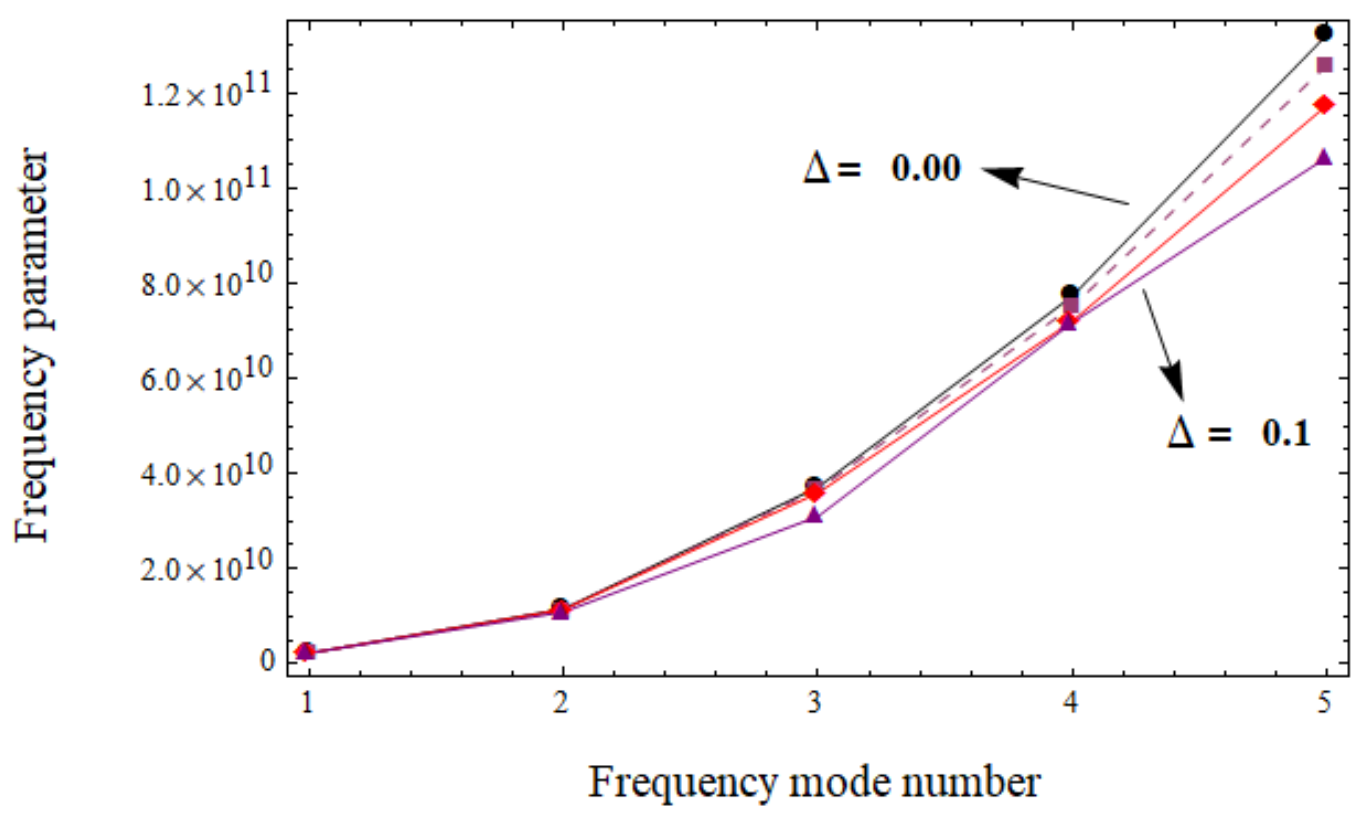

Figure 4:

Natural frequency parameter values for various $\Delta$ parameter

As shown in the Table 4 and Fig. 4 , as the mode value increases, the natural vibration frequency value increases and as the $\Delta=\frac{e_{0} a}{L}$ parameter value increases, a slight decrease in the vibration frequency value is observed. 


\section{CONCLUSION}

As can be seen from this work, tables and graphs have been created by considering which parameters can affect the vibration frequency values of the system has created within the scope of this study. Buckyball has added to the functionally graded nanobeam via a spring mass system. Hence, it decreased of the natural frequency of the structural system and caused a significant increase on the dynamic response of the nanobeam. By changing the $\beta$ and $\Delta$ parameters, their effect on the frequency of vibration has been observed.

- In the first part of this study, the value of $\beta$ was changed at close intervals. As a result of this change, it has been observed that the vibration frequency values are the highest in the first mode and continue to decrease in the progressive mode values.

- The $\Delta$ parameter was modified in the second part of the study, and the influence on vibration frequency value was noticed. As a result, as the $\Delta$ parameter value increase, the initial mode value achieves the highest vibration frequency value, while the subsequent mode values achieve lower vibration frequency values.

\section{CONFLICT OF INTEREST}

The author(s) confirm that there is no known conflict of interest or common interest with any institution/organization or person.

\section{AUTHOR CONTRIBUTION}

Togay KÜPELİ: Critical Review of Intellectual Content, Establishment of Article Draft, Final Consent and Full Responsibility.

Yakup Harun ÇAVUŞ: Data Collection, Data Analysis, Interpretation and Final Consent. Büşra UZUN: Data Analysis, Design Processes and Final Consent.

Mustafa Özgür YAYLI: Identification and Management of Conceptual and Design Processes of the Paper.

\section{REFERENCES}

1. Akbaş, Ş. D., (2019) Axially Forced Vibration Analysis of Cracked a Nanorod. Journal of Computational Applied Mechanics, 50(1), 63-68. doi:10.22059/jcamech.2019.281285.392

2. Akbaş, Ş. D. (2019) Longitudinal forced vibration analysis of porous a nanorod. Mühendislik Bilimleri ve Tasarım Dergisi,7 (4) , 736-743. DOI: 10.21923/jesd.553328

3. Akbas, S. D. (2020) Modal analysis of viscoelastic nanorods under an axially harmonic load. Advances in Nano Research, 8(4), 277-282. doi: 10.12989/ANR.2020.8.4.277.

4. Alimoradzadeh, M. and Akbaş, Ş. D. (2021) Superharmonic and subharmonic resonances of atomic force microscope subjected to crack failure mode based on the modified couple stress theory, European Physical Journal Plus, Vol. 136, no. 5. https://doi.org/10.1140/epjp/s13360-021-01539-0

5. Aydogdu, M. (2009) A general nonlocal beam theory: its application to nanobeam bending, buckling and vibration, Physica E 41, 1651-1655. DOI:10.1016/j.physe.2009.05.014

6. Civalek, Ö., Uzun, B., \& Yayl1, M. Ö. (2020) Stability analysis of nanobeams placed in electromagnetic field using a finite element method. Arabian Journal of Geosciences, 13(21), 1-9. https://doi.org/10.1007/s12517-020-06188-8 
7. Civalek, Ö., Demir, Ç. (2011) Bending analysis of microtubules using nonlocal EulerBernoulli beam theory, Appl. Math. Model, 35, 2053-2067. https://doi.org/10.1016/j.apm.2010.11.004

8. Civalek, Ö., Akgöz, B. (2010) Free vibration analysis of microtubules as cytoskeleton components: nonlocal Euler-Bernoulli beam modeling, Sci. Iranica Trans. B: Mech. Eng., $17,367-375$

9. Eltaher, M.A., Emam, S.A. (2013) Mahmoud, F.F., Static and stability analysis of nonlocal functionally graded nanobeams. Compos. Struct, 96, 82-88. doi: 10.1016/j.compstruct.2012.09.030.

10. Eringen, A. C. (1972) Nonlocal polar elastic continua. International Journal of Engineering Science, 10, 1-16. https://doi.org/10.1016/0020-7225(72)90070-5.

11. Eringen, A. C. (1983) on differential equations of nonlocal elasticity and solutions of screw dislocation and surface waves, J. Appl. Phys. 54 4703-4710. https://doi.org/10.1063/1.332803

12. Liu, T., Hai, M., Zhao, M. (2008) Delaminating buckling model based on nonlocal Timoshenko beam theory for microwedge indentation of a film/substrate system, Eng. Fract. Mech. 75, 4909-4919. doi:10.1016/j.engfracmech.2008.06.021.

13. Lu, P., Lee, H.P., Lu, C., Zhang, P.Q. (2006) Dynamic properties of flexural beams using a nonlocal elasticity model, J. Appl. Phys., 99, 73510-73518. https://doi.org/10.1063/1.2189213

14. Murmu, T., Adhikari, S., Wang, C.Y. (2011) Torsional vibration of carbon nanotubebuckyball systems based on nonlocal elasticity theory, Physica E Low-dimensional Systems and Nanostructures 43(6):1276-1280. DOI:10.1016/j.physe.2011.02.017

15. Murmu, T., Pradhan, S.C. (2009) Small-scale effect on the vibration of nonuniform nanocantilever based on nonlocal elasticity theory, Physica E, 41, 1451-1456. https://doi.org/10.1016/j.physe.2009.04.015.

16. Mustafa Arda \& Metin Aydogdu (2020) Vibration analysis of carbon nanotube mass sensors considering both inertia and stiffness of the detected mass, Mechanics Based Design of Structures and Machines. 1-17. doi:10.1080/15397734.2020.1728548.

17. Narendar, S. (2011) Buckling analysis of micro-/nano-scale plates based on two variable refined plate theory incorporating nonlocal scale effects, Compos. Struct, 93, 3093-3103. DOI:10.1016/j.compstruct.2011.06.028

18. Özgür Yayl1, M., \& Erdem Çerçevik, A. (2015). Axial vibration analysis of cracked nanorods with arbitrary boundary conditions. Journal of Vibroengineering, 17(6), 2907-2921.

19. Pradhan, S.C., Phadikar, J.K. (2009) Nonlocal elasticity theory for vibration of nanoplates. $J$. Sound Vib. 325, 206-223. DOI:10.1016/j.jsv.2009.03.007.

20. Rahmani, O., Pedram, O. (2014) Analysis and modeling the size effect on vibration of functionally graded nanobeams based on nonlocal Timoshenko beam theory, Int. J. Eng. Sci, 77, 55-70. DOI:10.1016/j.ijengsci.2013.12.003

21. Reddy, J.N. (2007) Nonlocal theories for bending, buckling and vibration of beams, Int. J. Eng. Sci.45, 288-307. DOI:10.1016/j.ijengsci.2007.04.004

22. Reddy J. N., Pang, S. D. (2008) Nonlocal continuum theories of beam for the analysis of carbon nanotubes,. Journal of Applied Physics, 103, 1-16. DOI:10.1063/1.2833431 
23. Setoodeh, A.R., Khosrownejad, M., Malekzadeh, P. (2011) Exact nonlocal solution for post buckling of single-walled carbon nanotubes. Physica E, 43, 1730-1737. https://doi.org/10.1016/j.physe.2011.05.032.

24. Shen, L., Shen, H.S., Zhang, C.L. (2010) Nonlocal plate model for nonlinear vibration of single layer graphene sheets in thermal environments, Comput. Mater. Sci., 48, 680-685. https://doi.org/10.1016/j.commatsci.2010.03.006.

25. Thai, H.T. (2012) A nonlocal beam theory for bending, buckling, and vibration of nanobeams. Int. J. Eng. Sci., 52, 56-64. DOI: 10.1016/j.ijengsci.2011.11.011

26. Uzun, B., Yaylı, M. Ö., \& Deliktaş, B. (2019). Free vibration of FG nanobeam using a finiteelement method. Micro \& Nano Letters, 15(1), 35-40. doi:10.1049/mnl.2019.0273.

27. Uzun, B., Civalek, Ö., \& Yayl1, M. Ö. (2020). Vibration of FG nano-sized beams embedded in Winkler elastic foundation and with various boundary conditions. Mechanics Based Design of Structures and Machines, 1-20. DOI: 10.1080/15397734.2020.1846560

28. Uzun, B., Yayl1, M. Ö. (2020) Nonlocal vibration analysis of Ti-6Al-4V/ZrO 2 functionally graded nanobeam on elastic matrix. Arabian Journal of Geosciences 13.4, 1-10. https://doi.org/10.1007/s12517-020-5168-4

29. Yayli, M.Ö. (2015) Buckling Analysis of a Rotationally Restrained Single Walled Carbon Nanotube, Acta Physica Polonica A, 127, 3, 678-683. DOI:10.24107/ijeas.252144

30. Yayli, M.Ö. (2015) Stability analysis of gradient elastic microbeams with arbitrary boundary conditions, Journal of Mechanical Science and Technology, 29, 8, 3373-3380. https://doi.org/10.1007/s12206-015-0735-4

31. Yayli, M.Ö. (2016). Buckling analysis of a rotationally restrained single walled carbon nanotube embedded in an elastic medium using nonlocal elasticity. International Journal of Engineering and Applied Sciences, 8(2), 40-50. DOI: 10.24107/ijeas.252144

32. Yayli, M. Ö. (2017). A compact analytical method for vibration of micro-sized beams with different boundary conditions. Mechanics of Advanced Materials and Structures, 24(6), 496508. DOI: $10.1080 / 15376494.2016 .1143989$.

33. Yayl1, M. Ö. \& Yerel Kandemir, S. (2017). Bending Analysis of A Cantilever Nanobeam With End Forces By Laplace Transform. International Journal of Engineering and Applied Sciences, Volume: 9 Issue: 2, 103-111. DOI: 10.24107/ijeas.314635

34. Yayli, M. Ö. (2018). Torsional vibration analysis of nanorods with elastic torsional restraints using non-local elasticity theory. Micro \& Nano Letters, 13(5), 595-599. doi: 10.1049/mnl.2017.0751

35. Yayli, M. Ö. (2018). Free vibration analysis of a single-walled carbon nanotube embedded in an elastic matrix under rotational restraints. Micro \& Nano Letters, 13(2), 202-206. doi: $10.1049 / \mathrm{mnl} .2017 .0463$

36. Yayl1, M. Ö., Uzun, B., \& Deliktaş, B. (2021). Buckling analysis of restrained nanobeams using strain gradient elasticity. Waves in Random and Complex Media, 1-20. DOI: $10.1080 / 17455030.2020 .1871112$

37. Wang, C.M., Kitipornchai, S., Lim, C.W., Eisenberger, M. (2008). Beam bending solutions based on nonlocal Timoshenko beam theory, J. Eng. Mech., 134, 475-481. DOI:10.1061/(ASCE)0733-9399(2008)134:6(475) 
